\title{
Reexamining the word length effect in visual word recognition: New evidence from the English Lexicon Project
}

\author{
BORIS NEW \\ Université René Descartes-Paris 5, Boulogne-Billancourt, France \\ LUDOVIC FERRAND \\ CNRS and Université René Descartes-Paris 5, Boulogne-Billancourt, France \\ CHRISTOPHE PALLIER \\ INSERM, U562 Service Hospitalier Frédéric Joliot, Orsay, France \\ and \\ MARC BRYSBAERT \\ Royal Holloway, University of London, London, England
}

\begin{abstract}
In the present study, we reexamined the effect of word length (number of letters in a word) on lexical decision. Using the English Lexicon Project, which is based on a large data set of over 40,481 words (Balota et al., 2002), we performed simultaneous multiple regression analyses on a selection of 33,006 English words (ranging from 3 to 13 letters in length). Our analyses revealed an unexpected pattern of results taking the form of a U-shaped curve. The effect of number of letters was facilitatory for words of 3-5 letters, null for words of 5-8 letters, and inhibitory for words of 8-13 letters. We also showed that printed frequency, number of syllables, and number of orthographic neighbors all made independent contributions. The length effects were replicated in a new analysis of a subset of 3,833 monomorphemic nouns (ranging from 3 to 10 letters), and also in another analysis based on 12,987 bisyllabic items (ranging from 3 to 9 letters). These effects were independent of printed frequency, number of syllables, and number of orthographic neighbors. Furthermore, we also observed robust linear inhibitory effects of number of syllables. Implications for models of visual word recognition are discussed.
\end{abstract}

The effects of word length on visual word recognition have been examined with a variety of techniques (such as perceptual identification, lexical decision, naming, eye tracking), but the results have been inconsistent, ranging from inhibitory (longer words are harder) to null effects. Word length can be based on orthographic measures (number of letters) or phonological measures (number of phonemes and syllables). These different measures are generally highly intercorrelated, and they also correlate with other variables (such as the number of orthographic neighbors and the printed frequency) that influence word recognition. In the present study, we are primarily interested in word length as measured by the number of letters.

We are grateful to David Balota, Carol Whitney, Johannes Ziegler, and two anonymous reviewers for comments on an earlier version of this manuscript. Correspondence may be addressed to B. New, Laboratoire de Psychologie Expérimentale, CNRS et Université René DescartesParis 5, 71 Avenue Edouard Vaillant, 92774 Boulogne-Billancourt, France (e-mail: boris.new@univ-paris5.fr).

\section{Early Studies Using Perceptual Identification}

Perceptual identification was the main dependent variable in the first studies of visual word recognition. Some of these studies included word length as an independent variable. As can been seen in Table 1, these experiments yielded a mixture of null effects and inhibitory length effects. A problem with the perceptual identification task, however, is that interpretation of the data is difficult. Because of the offline nature of the dependent variable (percentage of words recognized), participants may have tried to guess the word on the basis of the few letters they were able to identify. As a result, perceptual identification was progressively abandoned in favor of tasks measuring online processing (Monsell, 1991).

\section{More Recent Studies Using Tasks Recording Online Reaction Times}

More recent studies using online reaction times, such as those obtained in lexical decision, naming, and eye movement recording, have also reported mixed results (again see Table 1). Hudson and Bergman (1985), for example, obtained reliable inhibitory length effects for words with 4-12 letters in naming (the size of the effect was $3.2 \mathrm{msec}$ 
Table 1 Summary of Empirical Investigations of the Length Effects on Adults with Foveally Presented Words

\begin{tabular}{|c|c|c|c|c|}
\hline Study & Experiment & Language & Length & Length Effect \\
\hline \multicolumn{5}{|c|}{ Perceptual Identification } \\
\hline Howes \& Solomon (1951) & 2 & English & $6-12$ & Null \\
\hline McGinnies, Comer, \& Lacey (1952) & 1 & English & $5 ; 7 ; 9 ; 11$ & Inhibitory \\
\hline Postman \& Adis-Castro (1957) & 1 & English & $5 ; 7 ; 9 ; 11$ & Inhibitory \\
\hline Newbigging \& Hay (1962) & 1 & English & $4 ; 7 ; 10$ & Inhibitory \\
\hline Doggett \& Richards (1975) & 1 & English & $3 ; 4 ; 5 ; 6 ; 7 ; 8 ; 9 ; 10 ; 11$ & Null \\
\hline Doggett \& Richards (1975) & 2 & English & $4 ; 7 ; 8 ; 10$ & Inhibitory trend \\
\hline Richards \& Heller (1976) & $1 ; 3 ; 4$ & English & $3 ; 4 ; 6 ; 7$ & Null \\
\hline Bijeljac-Babic, Millogo, Farioli, \& Grainger (2004) & 1 & French & $3 ; 4 ; 5 ; 6 ; 7 ; 8$ & Null \\
\hline \multicolumn{5}{|c|}{ Lexical Decision } \\
\hline Frederiksen \& Kroll (1976) & 2 & English & $4-6$ & Null \\
\hline Richardson (1976) & 1 & English & $5-11$ & Null \\
\hline Hudson \& Bergman (1985) & $1 ; 2 ; 3 ; 4$ & Dutch & $4-12$ & Inhibitory \\
\hline O’Regan \& Jacobs (1992) & 1 & French & $4 ; 5 ; 7 ; 9 ; 11$ & Inhibitory \\
\hline Balota, Cortese, Sergent-Marshall, Spieler, \& Yap (2004) & 1 & English & $2 ; 3 ; 4 ; 5 ; 6 ; 7 ; 8$ & Inhibitory \\
\hline \multicolumn{5}{|c|}{ Naming } \\
\hline Frederiksen \& Kroll (1976) & 1 & English & $4 ; 5 ; 6$ & Inhibitory \\
\hline Richardson (1976) & 1 & English & $5-11$ & Inhibitory \\
\hline Hudson \& Bergman (1985) & $1 ; 2$ & Dutch & $4-12$ & Null \\
\hline O'Regan \& Jacobs (1992) & $2 \mathrm{a} ; 2 \mathrm{~b}$ & French & $4 ; 5 ; 7 ; 9 ; 11$ & Inhibitory \\
\hline Spieler \& Balota (1997) & 1 & English & $2 ; 3 ; 4 ; 5 ; 6 ; 7 ; 8$ & Inhibitory \\
\hline Weekes (1997) & 1 & English & $3 ; 4 ; 5 ; 6$ & Null \\
\hline Ziegler, Perry, Jacobs, \& Braun (2001) & 1 & German; English & $3 ; 4 ; 5 ; 6$ & Inhibitory \\
\hline Balota, Cortese, Sergent-Marshall, Spieler, \& Yap (2004) & 1 & English & $2 ; 3 ; 4 ; 5 ; 6 ; 7 ; 8$ & Inhibitory \\
\hline Bijeljac-Babic, Millogo, Farioli, \& Grainger (2004) & 1 & French & $3 ; 4 ; 5 ; 6 ; 7$ & Null \\
\hline \multicolumn{5}{|c|}{ Eye Movements } \\
\hline Vitu, O’Regan, \& Mittau (1990) & 1 & French & $5 ; 6 ; 7 ; 8 ; 9$ & Inhibitory \\
\hline Rayner, Sereno, \& Raney (1996) & 1 & English & $5 ; 6 ; 7 ; 8 ; 9 ; 10$ & Inhibitory \\
\hline Juhasz \& Rayner (2003) & 1 & English & $5 ; 6 ; 7$ & Inhibitory \\
\hline
\end{tabular}

per letter) and in lexical decision (no size was given), but researchers in two other studies (Frederiksen \& Kroll, 1976; Richardson, 1976) found length effects in naming but not in lexical decision.

Investigating word length and frequency effects, O'Regan and Jacobs (1992) found reliable inhibitory length effects in lexical decision and naming with words ranging from 4 to 11 letters. The effect size was around 15-19 msec per letter both in lexical decision and in naming. Furthermore, the authors showed that frequency and length did not interact.

Inhibitory effects have also been found in eye movement recordings of participants reading isolated words or normal text (Vitu, O'Regan, \& Mittau, 1990). Vitu et al. reported a significant increase of gaze duration and refixation probability with word length. Furthermore, there was no hint of any frequency $\times$ length interaction, thus replicating the results that O'Regan and Jacobs (1992) obtained in lexical decision and naming. Rayner, Sereno, and Raney (1996) also showed that length effects were obtained even when a single fixation was made on the word. Recently, Juhasz and Rayner (2003) found word length to be a significant predictor of gaze duration and total fixation duration, confirming Rayner et al.'s finding.

Testing naming performance on 2,820 single-syllable words, Spieler and Balota (1997) found a surprisingly large inhibitory influence of length in letters $(4.5 \%$ unique vari- ance, $6.3 \%$ for $\log$ frequency, and $2.2 \%$ for orthographic neighborhood size). In a cross-language study, comparing German and English cognates, Ziegler, Perry, Jacobs, and Braun (2001) found an inhibitory letter length effect in both languages (in a naming task with items from 3 to 6 letters), although the effect was stronger in German than in English. Furthermore, these effects were still significant when the number of orthographic neighbors was partialled out. Perry and Ziegler (2002) were able to simulate these results with both a German version and the English version of the DRC model. In a more recent study, testing 2,906 monosyllabic words with 30 young and 30 old participants, Balota, Cortese, Sergent-Marshall, Spieler, and Yap (2004) found a reliable inhibitory length effect in naming (for 2- to 8-letter words) and a reliable but smaller inhibitory effect for lexical decision in older participants but not in university students. In addition, the length effect was moderated by word frequency: It was significantly larger for low-frequency words than for high-frequency words. For university students, the length effect was even facilitatory when the analysis was limited to high-frequency words and lexical decision. Another important result of Balota et al. (2004) was that their length effect was obtained after partialling out the length in phonemes, suggesting that the letter length effect is not a phoneme length effect in disguise.

As can be seen in Table 1, the results of the different studies are inconsistent. 


\section{THE PRESENT STUDY \\ A Reexamination of the Length Effect in the Lexical Decision Task Based on the English Lexicon Project}

To further examine the influence of stimulus length on lexical decision times, we decided to make use of the recently published English Lexicon Project (ELP), which contains lexical decision and naming latency data for a large set of over 40,481 words (Balota et al., 2002). The ELP represents a collaborative effort among six different American universities to provide behavioral and descriptive lexical processing information. The lexical decision data are based on 10 to 35 observations per item (see the ELP Web site, elexicon.wustl.edu). Overall, 816 participants have provided data for this task. Each participant provided data for a subset of approximately 3,000 of the 40,481 tested words. The nonwords were pronounceable and based on the words; they did not include pseudohomophones.

In the present study, we selected 33,006 English monoand polysyllabic words, removing abbreviations, proper names, and items having less than 10 correct observations. Critically, the present corpus allowed us to make a number of methodological improvements over previous studies testing the word length effect. First, the words ranged from 3 letters to 13 letters in length, allowing us to look at the entire range of word lengths. Second, the number of words was much larger than those used in previous studies. This very large number of items allowed us to look at the word length effects for every length when the influence of other factors was partialled out.

\section{Method}

The stimuli were taken from the English Lexicon Project (Balota et al., 2002; elexicon.wustl.edu).

\section{Results}

Analysis 1: Descriptive statistics. In the first analysis, we simply plotted the correct lexical decision latencies as a function of the number of letters (ranging from 3 to 13 letters).

As Figure 1 shows, reaction times increased with length $(r=.51, p<.001)$. This analysis, however, did not control for word frequency or number of orthographic neighbors, two variables that are assumed to play a more fundamental role in lexical decision than word length. Table 2 presents the raw correlation matrix of reaction times, length in letters, log of HAL frequency, number of syllables, and log of the number of orthographic neighbors. To get a better idea of the unique contribution of each of the predictor variables, we ran multiple regression analyses.

Analysis 2: Simultaneous multiple regression. In order to test the resistance of the effect of number of letters to number of syllables, number of orthographic neighbors, and printed frequency, we entered all predictors in a multiple regression analysis for the 33,006 words taken from the ELP. On average, 29 observations were collected per word. The dependent variable was raw reaction times. ${ }^{1}$ The number of syllables for each word was given by CELEX (Baayen, Piepenbrock, \& Gulikers, 1995), and the number of orthographic neighbors was given by the ELP. As for frequency, we took log HAL frequencies (Lund \&

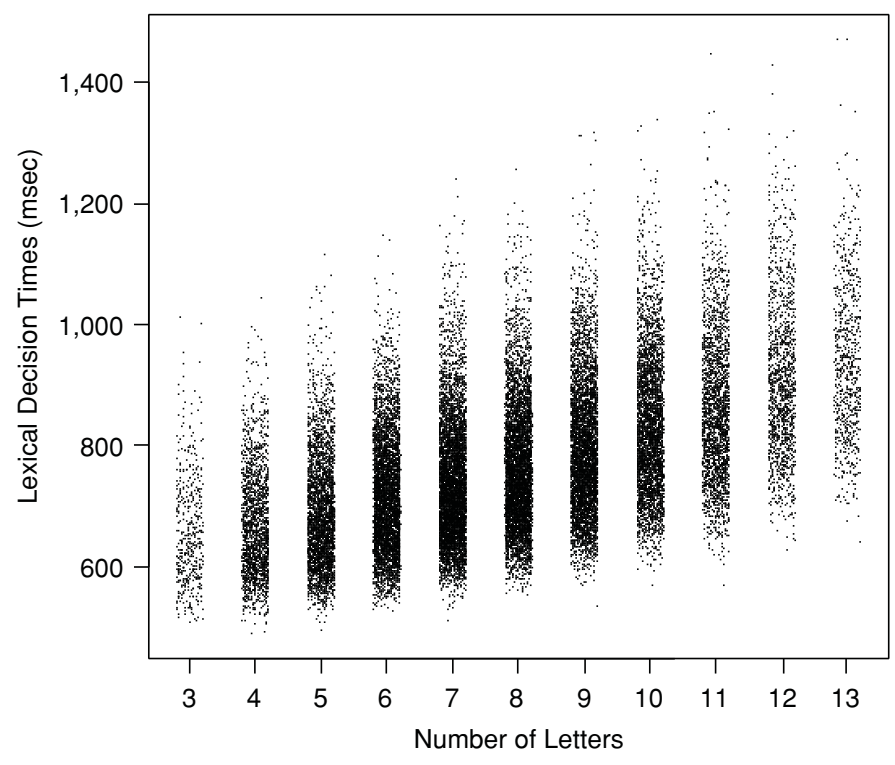

Figure 1. Length effect based on the words from the English Lexicon Project corpus (Balota et al., 2002) for words with lengths from 3 to 13 letters (tested in the lexical decision task). Each dot corresponds to a distinct word. Overall, 33,006 words are plotted on the graph (1- and 2-letter words were excluded from the analysis). 
Table 2

Correlations Between Correct Lexical Decision Times (RTs Taken

From the English Lexicon Project; Balota et al., 2002) and

Length in Letters, Printed Frequency (Log), Number of

Orthographic Neighbors $(\log )$, and Number of Syllables

\begin{tabular}{lccccc}
\hline & $\begin{array}{c}\text { No. of } \\
\text { Neighbors } \\
(\log 10)\end{array}$ & $\begin{array}{c}\text { No. of } \\
\text { Letters }\end{array}$ & $\begin{array}{c}\text { No. of } \\
\text { Syllables }\end{array}$ & $\begin{array}{c}\text { Printed } \\
\text { Frequency } \\
(\log 10)\end{array}$ & RTs \\
\hline No. of neighbors & 1 & & & & \\
No. of letters & -0.63 & 1 & & & \\
No. of syllables & -0.56 & 0.81 & 1 & & \\
Printed frequency & 0.30 & -0.32 & -0.23 & 1 & \\
RTs & -0.40 & 0.53 & 0.51 & -0.62 & 1 \\
\hline
\end{tabular}

Note-All correlations are significant at .001 .

Burgess, 1996) provided in the ELP. Table 3 shows the results of the simultaneous multiple regression analysis on the correct lexical decision times. Other factors such as bigram frequency (per position and not per position) were not included in the analysis, because they were not significant. The number of phonemes was not included either, because it explained less variance than did the length in characters and correlated strongly $(r=.9)$ with it. The overall regression equation was significant, and the model accounted for $53.4 \%$ of the variance in the data $[F(4,33001)=9,455, p<.001]$. The results show that number of letters, printed frequency, and number of syllables made significant independent contributions toward the predicted lexical decision latencies. Of interest here is the fact that the inhibitory effect of number of letters was robust and not a confound of other lexical factors.

To make sure that the data in Table 3 were not due to a speed-accuracy trade-off, we computed the correlation between the average correct RT and the average accuracy per length. This correlation was negative and substantial $(r=-.81)$, as would be expected when both speed and accuracy point to the conclusion that longer words are harder to recognize.

Analysis 3: More detailed analyses of the length effect. To get a more detailed picture of the effect of word length over the entire range, we ran multiple regression analyses on all successive pairs of word lengths, starting from 3-4 letters and ending at 12-13 letters (Table 4). The results showed that printed frequency, number of neighbors, and number of syllables made consistent contributions throughout the range of lengths. With respect to the number of letters, however, the results showed an unex- pected pattern. The effect of word length was facilitatory for words with $3-5$ letters, null for words with 5-8 letters, and inhibitory for words with 8-13 letters. This means that the relationship between lexical decision times and word lengths is U-shaped (longer times for short and long words than for words going from 5 to 8 letters).

Figure 2 shows the amplitude and the direction of the length effect for each pair of lengths. It is very clear from this figure that the pattern goes from facilitation to inhibition passing through a region of null effects. The quadratic effect of length was confirmed in a regression analysis with the whole data set showing that term "length ${ }^{2}$ " had a significant contribution $[t(33001)=29.7]$.

Analysis 4: Simultaneous multiple regression on a subset of the stimuli (nouns only). In the previous analyses, we entered all usable words from the ELP. In order to ensure that the finding in Figure 2 was not due to a confounding variable such as the grammatical category (Perry \& Ziegler, 2002), we ran similar analyses on a subset of nouns. We eliminated all inflected forms (plurals and verb forms), morphologically complex words (defined by CELEX), and stimuli other than nouns (or stimuli having more than one grammatical category). From the original sample of 33,006 stimuli, we retained 3,833 items. This selection also restricted the range of word lengths, which now varied from 3 to 10 letters. Table 5 shows the results of the simultaneous multiple regression analyses on the correct lexical decision times. The findings obtained for this subset of stimuli are very similar to those obtained for the larger set of words. Printed frequency and number of syllables made significant independent contributions throughout the range of lengths, and the word length effect

Table 3

Raw Regression Coefficients (With Standardized Regression Coefficients in Parentheses) From Simultaneous Multiple Regression Analysis on the Lexical Decision Latencies Based on 33,006 Words Taken From the English Lexicon Project (Balota et al., 2002)

\begin{tabular}{lccrc}
\hline \multicolumn{1}{c}{ Predictor } & Estimate & Std. Error & $t$ & $p$ \\
\hline $\log 10(\mathrm{HAL}+1)$ & $-63.41(-0.51)$ & 0.50 & -127.77 & .001 \\
$\log 10($ neighbors +1$)$ & $-0.22(\geq 0.01)$ & 1.87 & -0.12 & $>.1$ \\
No. of letters & $8.07(0.15)$ & 0.37 & 24.09 & .001 \\
No. of syllables & $32.13(0.27)$ & 0.75 & 43.53 & .001 \\
\hline
\end{tabular}


Table 4

Raw Regression Coefficients (With Standardized Regression Coefficients in Parentheses) From Simultaneous Multiple Regression Analyses on the Lexical Decision Latencies Based on 33,006 Words Taken From the English Lexicon Project (Balota et al., 2002) for Each Range of Length

\begin{tabular}{cccccccccc}
\hline $\begin{array}{c}\text { Length } \\
\text { Range }\end{array}$ & $\begin{array}{l}\text { No. of } \\
\text { Words }\end{array}$ & \multicolumn{2}{c}{$\begin{array}{c}\text { Printed Frequency } \\
(\log 10)\end{array}$} & \multicolumn{2}{c}{$\begin{array}{c}\text { No. of } \\
\text { Syllables }\end{array}$} & \multicolumn{2}{c}{$\begin{array}{c}\text { No. of } \\
\text { Neighbors }(\log 10)\end{array}$} & \multicolumn{2}{c}{ No. of Letters } \\
\hline $3-4$ & $466-1,814$ & $-52.92^{* * * *}$ & $(-0.42)$ & $16.03^{* * *}$ & $(0.14)$ & $-37.01^{* * *}$ & $(-0.10)$ & $-19.09^{* * * *}$ & $(-0.35)$ \\
$4-5$ & $1,814-3,059$ & $-57.86^{* * *}$ & $(-0.46)$ & $19.33^{* * *}$ & $(0.16)$ & $-35.62^{* * *}$ & $(-0.09)$ & $-15.91^{* * *}$ & $(-0.29)$ \\
$5-6$ & $3,059-4,494$ & $-62.14^{* * *}$ & $(-0.50)$ & $21.20^{* * *}$ & $(0.18)$ & $-33.93^{* * *}$ & $(-0.09)$ & -1.34 & $(-0.02)$ \\
$6-7$ & $4,494-5,397$ & $-63.11^{* * *}$ & $(-0.51)$ & $25.05^{* * *}$ & $(0.21)$ & $-34.17^{* * *}$ & $(-0.09)$ & -2.66 & $(-0.05)$ \\
$7-8$ & $5,397-5,258$ & $-63.30^{* * *}$ & $(-0.51)$ & $29.71^{* * *}$ & $(0.25)$ & $-39.67^{* * *}$ & $(-0.10)$ & 2.79 & $(0.05)$ \\
$8-9$ & $5,258-4,655$ & $-64.72^{* * *}$ & $(-0.52)$ & $34.19^{* * *}$ & $(0.29)$ & $-45.05^{* * *}$ & $(-0.12)$ & $6.14^{* * *}$ & $(0.11)$ \\
$9-10$ & $4,655-3,535$ & $-67.08^{* * *}$ & $(-0.54)$ & $33.07^{* * *}$ & $(0.28)$ & $-40.37^{* * *}$ & $(-0.11)$ & $19.03^{* * *}$ & $(0.35)$ \\
$10-11$ & $3,535-2,244$ & $-69.65^{* * *}$ & $(-0.56)$ & $28.49^{* * *}$ & $(0.24)$ & $-32.40^{* *}$ & $(-0.09)$ & $13.73^{* * *}$ & $(0.25)$ \\
$11-12$ & $2,244-1,353$ & $-74.69^{* * *}$ & $(-0.60)$ & $26.62^{* * *}$ & $(0.23)$ & -27.82 & $(-0.07)$ & $32.06^{* * *}$ & $(0.59)$ \\
$12-13$ & $1,353-731$ & $-78.70^{* * *}$ & $(-0.63)$ & $23.00^{* * *}$ & $(0.20)$ & -44.57 & $(-0.12)$ & $19.40^{* * *}$ & $(0.36)$ \\
\hline
\end{tabular}

${ }^{* *} p<.01 . \quad{ }^{* * *} p<.001$.

retained its surprising $U$ curve, going from facilitatory for words with 3-5 letters, to null for words with 5-8 letters, to inhibitory for words with 8-10 letters.

Analysis 5: Simultaneous multiple regression on a subset of stimuli controlling for the number of syllables. To examine whether the shape of the word length function might be an artifact of the number of syllables (e.g., because 5-letter words are more likely to be bisyllabic than 3-letter words), we ran a new analysis on the 12,987 bisyllabic items. As Table 6 shows, we replicated the U-shaped pattern obtained previously: the length effect (in number of letters) was facilitatory for words with 3-5 letters, null for words with 5-8 letters, and inhibitory for words with $8-9$ letters. This result clearly demonstrates that the U-shaped function was not a confound of the number of syllables.

\section{Discussion}

In the present study, we re-examined the effect of number of letters in lexical decision. We used the English Lexicon Project based on a large data set of over 40,481 words (Balota et al., 2002). Our multiple regression analyses were based on a selection of 33,006 English words (ranging from 3 to 13 letters). These analyses revealed an unexpected pattern of results taking the form of a U-shaped curve: Decision latencies were longer to short and to long words than to words from 5 to 8 letters in length. This finding remained when the analysis was restricted to a subset of 3,833 monomorphemic nouns (ranging from 3 to 10 letters) or 12,987 bisyllabic words. The length effect was independent of printed frequency, number of syllables, and number of orthographic neighbors. This U-shaped pattern is particularly interesting be-

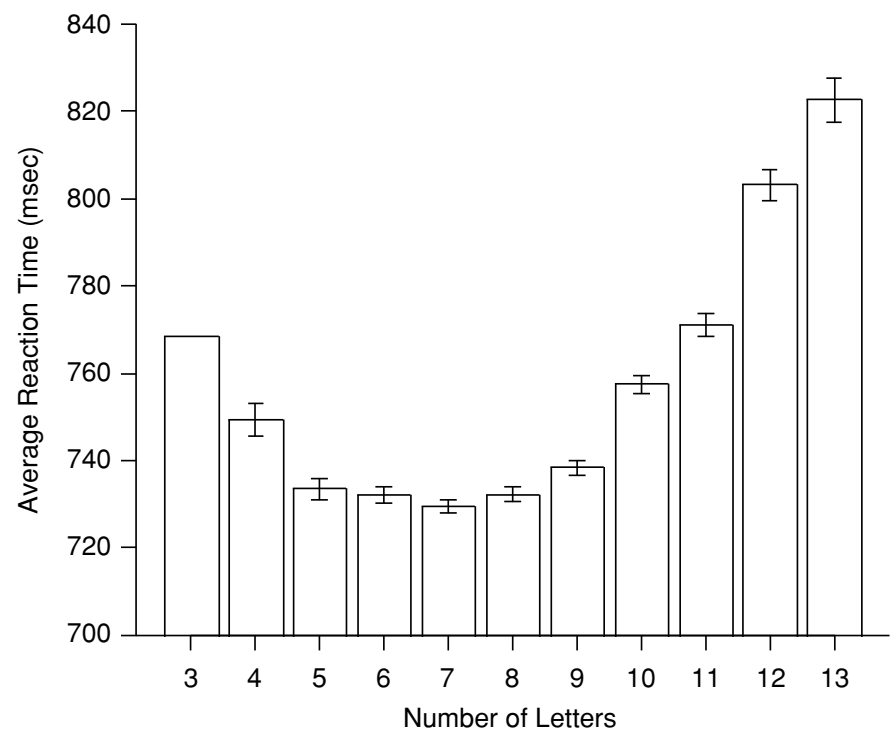

Figure 2. Average reaction time and $95 \%$ confidence interval for words with lengths from 3 to 13 letters if length was the only factor having an influence (all other factors have been partialled out). 
Table 5

Raw Regression Coefficients (With Standardized Regression Coefficients in Parentheses) From Simultaneous Multiple Regression Analyses on the Lexical Decision Latencies Based on a Subset of 3,833 Monomorphemic Nouns Taken From the English Lexicon Project (Balota et al., 2002) for Each Range of Length

\begin{tabular}{lcccccccrr}
\hline $\begin{array}{l}\text { Length } \\
\text { Range }\end{array}$ & $\begin{array}{c}\text { No. of } \\
\text { Words }\end{array}$ & \multicolumn{2}{c}{$\begin{array}{c}\text { Printed Frequency } \\
(\log 10)\end{array}$} & \multicolumn{2}{c}{$\begin{array}{c}\text { No. of } \\
\text { Syllables }\end{array}$} & \multicolumn{2}{c}{$\begin{array}{c}\text { No. of } \\
\text { Neighbors }(\log 10)\end{array}$} & No. of Letters \\
\hline $3-4$ & $131-445$ & $-62.72^{* * *}$ & $(-0.45)$ & 3.48 & $(0.3)$ & $-53.35^{* *}$ & $(-0.16)$ & $-17.90^{*}$ & $(-0.30)$ \\
$4-5$ & $445-622$ & $-68.17^{* * *}$ & $(-0.49)$ & $15.90^{* * *}$ & $(0.13)$ & $-47.07^{* * *}$ & $(-0.14)$ & $-16.11^{*}$ & $(-0.27)$ \\
$5-6$ & $622-801$ & $-70.64^{* * *}$ & $(-0.51)$ & $20.30^{* * *}$ & $(0.16)$ & $-39.64^{* * *}$ & $(-0.12)$ & 0.91 & $(0.02)$ \\
$6-7$ & $801-702$ & $-72.98^{* * *}$ & $(-0.52)$ & $22.01^{* * *}$ & $(0.17)$ & $-36.62^{* * *}$ & $(-0.11)$ & 7.36 & $(0.12)$ \\
$7-8$ & $702-512$ & $-76.44^{* * *}$ & $(-0.55)$ & $24.83^{* * *}$ & $(0.20)$ & $-36.04^{*}$ & $(-0.11)$ & 4.48 & $(0.08)$ \\
$8-9$ & $512-327$ & $-72.98^{* * *}$ & $(-0.52)$ & $30.24^{* * *}$ & $(0.24)$ & -33.82 & $(-0.10)$ & $18.81^{* *}$ & $(0.32)$ \\
$9-10$ & $327-156$ & $-73.18^{* * *}$ & $(-0.52)$ & $22.11^{* * *}$ & $(0.18)$ & -22.99 & $(-0.07)$ & $20.04^{*}$ & $(0.34)$ \\
\hline$*$
\end{tabular}

${ }^{*} p<.05 . \quad{ }^{* *} p<.01 . \quad{ }^{* * *} p<.001$

cause it could explain the mixed results obtained before (see Table 1). The fact that the reported length effects can be null or inhibitory could be partly explained by the different lengths used by the investigators in their studies. As a matter of fact, a close rereading of the previous evidence pointed to some hints with respect to the inverse length effect for short words. As we indicated in our introduction, Balota et al. (2004) reported in an experiment with single-syllable words ranging from 2 to 8 letters a facilitatory length effect for high-frequency words (which probably had a reduced length range) in university students. They also reported an inhibitory effect for low-frequency words. Similarly, although not discussed by these authors, O'Regan and Jacobs (1992) found a null effect of word length for words of 4 and 5 letters in a lexical decision experiment when the eyes fixated the middle position of the word.

Implications for models of visual word recognition (silent reading). The implicit assumption in models of visual word recognition has been that either word length has no effect on word recognition (e.g., because letters are processed in parallel; see Grainger \& Jacobs, 1996) or the effect is inhibitory (e.g., because the nonlexical route for low-frequency words processes letter strings sequentially in a left-to-right cycle; see Coltheart, Rastle, Perry, Langdon, \& Ziegler, 2001). The U-shaped curve discovered here requires us to revisit this assumption. Below, we offer some ideas regarding the factors that might be involved.
A first factor that is bound to play a role is the decrease of visual acuity outside the fixation location (O'Regan \& Jacobs, 1992). Letters are more difficult to perceive the farther they are from the fixation point. This has a particular cost for the letters presented to the left of fixation, because here the farthest letters are the first letters of the word (Whitney \& Lavidor, 2004). Surprisingly, however, the visual acuity factor only seems to become dominant for word lengths of 9 letters and more, even though the drop of visual acuity is known to start within foveal vision and to be roughly linear (Nazir, Jacobs, \& O'Regan, 1998).

Another factor likely to play a role is the fact that in reading, most forward saccades (76\%) are from 5 to 11 character spaces long, with an average of 8 spaces. This means that in reading, words with a length of 6-9 letters have the highest chances of being processed after a single fixation on them. Shorter words are skipped quite often and longer words are refixated regularly. Nazir, Ben-Boutayab, Decoppet, Deutsch, and Frost (2004) have made the case that low-level perceptual learning plays a role in visual word recognition, in particular in establishing the automaticity of parallel word recognition. They point out that parallel word processing is observed only in a small region of the visual field, with highly skilled readers and with a familiar font. For Nazir et al. (2004), the extent of foveal parallel word processing depends on the number of times a word has been identified after a single

Table 6

Raw Regression Coefficients (With Standardized Regression Coefficients in Parentheses) From Simultaneous Multiple Regression Analyses on the Lexical Decision Latencies Based on a Subset of 12,987 Bisyllabic Nouns Taken From the English Lexicon Project (Balota et al., 2002) for Each Range of Length

\begin{tabular}{cccccccr}
\hline $\begin{array}{c}\text { Length } \\
\text { Range }\end{array}$ & $\begin{array}{c}\text { No. of } \\
\text { Words }\end{array}$ & \multicolumn{2}{c}{$\begin{array}{c}\text { Printed Frequency } \\
(\log 10)\end{array}$} & \multicolumn{2}{c}{$\begin{array}{c}\text { No. of } \\
\text { Neighbors }(\log 10)\end{array}$} & \multicolumn{2}{c}{ No. of Letters } \\
\hline $3-4$ & $243-1,218$ & $-68.19^{* * *}$ & $(-0.65)$ & $-42.90^{* * *}$ & $(-0.12)$ & $-14.96^{* * *}$ & $(-0.19)$ \\
$4-5$ & $1,218-3,086$ & $-65.01^{* * *}$ & $(-0.62)$ & $-37.49^{* * *}$ & $(-0.10)$ & $-3.40^{* * *}$ & $(-0.04)$ \\
$5-6$ & $3,086-3,941$ & $-62.80^{* * *}$ & $(-0.60)$ & $-36.61^{* * *}$ & $(-0.10)$ & -1.57 & $(-0.02)$ \\
$6-7$ & $3,941-2,807$ & $-62.38^{* * *}$ & $(-0.60)$ & $-41.90^{* * *}$ & $(-0.11)$ & 0.47 & $(0.01)$ \\
$7-8$ & $2,807-1,283$ & $-61.27^{* * *}$ & $(-0.59)$ & $-55.06^{* * *}$ & $(-0.15)$ & 1.00 & $(0.01)$ \\
$8-9$ & $1,283-409$ & $-60.00^{* * *}$ & $(-0.58)$ & $-28.94^{* * *}$ & $(-0.08)$ & $26.91^{* * *}$ & $(0.35)$ \\
${ }^{* * * *} p<.001$. & & & & & & &
\end{tabular}


fixation on it. In this respect, it may also be interesting to note that word lengths from 5 to 8 letters are the most frequently encountered in reading (see Table 4 : these four word lengths constituted a total of $55 \%$ of all the words that we entered in the analyses).

A final factor (or set of factors) that might be involved in the explanation of the word length effect is the similarity of the words and the nonwords for the different word lengths. Performance in a lexical decision task depends not only on the features of the word stimuli, but also on the features of the nonword stimuli and the overlap of these features for the different word lengths. For instance, many researchers make their nonwords by changing one letter of an existing word. On average, this will increase the similarity of the words and nonwords with increasing word length (the overlap between the initial word and the nonword will be $1 / 2$ for a 2 -letter word, ${ }^{2} / 3$ for a 3 -letter word, ..., ${ }^{12} / 13$ for a 13 -letter word). In addition, each nonword will have a word neighbor, irrespective of its length (in contrast to the real words, for which the number of neighbors becomes less than .25 for word lengths above 8 ).

A look at the characteristics of the nonwords in ELP confirms that some of the above correlations were present. The number of orthographic neighbors dropped from 5.8 for 3-letter nonwords to 1.4 for 7-letter nonwords and then reached a floor of more or less 1 for the remaining nonword lengths (the actual value was .9 for 13-letter nonwords, indicating that some of these nonwords were created by changing more than 1 letter of an existing word). Interestingly, although this characteristic of the nonwords could explain an inhibitory length effect (longer RTs for longer words due to the greater word/nonword overlap at the high end of the range), it would not seem able to explain the facilitatory length effect observed for the short words or the null effect for the midrange. Indeed, the RTs to the nonwords increased almost linearly from $726 \mathrm{msec}$ for 3-letter nonwords to $1,003 \mathrm{msec}$ for 13 -letter nonwords. Clearly, further research will be needed here to find out what exactly the effect of the nonword characteristics is on the word length effect in a lexical decision experiment.

Syllable length effects. In the present study, we observed a consistent inhibitory effect of the number of syllables, which amounted to some $20 \mathrm{msec}$ per syllable on average. To our knowledge, this is the first demonstration of a syllable length effect in a lexical decision task in English. One reason why this effect has not been noticed before may be that most visual recognition studies conducted in English were limited to monosyllabic words. The syllable effect was independent of printed frequency, number of letters, and number of orthographic neighbors. This finding confirms previous results obtained in French in lexical decision and naming (see Ferrand, 2000; Ferrand \& New, 2003). Ferrand and New (2003) obtained a syllable length effect in lexical decision (for low-frequency words), and this result was controlled for number of letters, number of orthographic neighbors, bigram frequency, initial phoneme, and initial syllable. This effect reminds us again that a major limitation of most existing models of visual word recognition is that they apply to monosyllabic words only (but see Ans, Carbonnel, \& Valdois, 1998).

\section{Conclusion}

Whatever the eventual interpretation will be, it is clear that the relationship between word length and lexical decision times is less straightforward than has been assumed. Mixed results have suggested no effect as well as an inhibitory effect, but the ELP data clearly show that for the words often used in word recognition experiments (i.e., words of 3-5 letters), the length effect is actually inverted. The only interpretations for this unexpected finding that we have at the moment refer to the fact that 5-letter words are much more common than 4- and 3-letter words (type frequency) and that short words are less likely to be fixated in reading (see Brysbaert, Drieghe, \& Vitu, in press, for the precise findings).

\section{REFERENCES}

Ans, B., Carbonnel, S., \& Valdois, S. (1998). A connectionist multipletrace memory model for polysyllabic word reading. Psychological Review, 105, 678-723.

BaAyen, R. H., Piepenbrock, R., \& Gulikers, L. (1995). The CELEX lexical database (Release 2; CD-ROM). Philadelphia: University of Pennsylvania, Linguistic Data Consortium.

Balota, D. A., Cortese, M. J., Hutchison, K. A., Neely, J. H., Nelson, D., Simpson, G. B., \& Treiman, R. (2002). The English Lexicon Project: A Web-based repository of descriptive and behavioral measures for 40,481 English words and nonwords. St. Louis: Washington University. Available at elexicon.wustl.edu.

Balota, D. A., Cortese, M. J., Sergent-Marshall, S. D., Spieler, D. H., \& YAP, M. J. (2004). Visual word recognition of single-syllable words. Journal of Experimental Psychology: General, 133, 283-316.

Bijeljac-Babic, R., Millogo, V., Farioli, F., \& Grainger, J. (2004). A developmental investigation of word length effects in reading using a new on-line word identification paradigm. Reading \& Writing, 17, 411-431.

Brysbaert, M., Drieghe, D., \& Vitu, F. (in press). Word skipping: Implications for theories of eye movement control in reading. In $\mathrm{G}$. Underwood (Ed.), Eye guidance in reading and scene perception (2nd ed.). Amsterdam: Elsevier.

Coltheart, M., Rastle, K., Perry, C., Langdon, R., \& Ziegler, J. (2001). DRC: A dual route cascaded model of visual word recognition and reading aloud. Psychological Review, 108, 204-256.

DoggetT, D., \& Richards, L. (1975). A reexamination of the effect of word length on recognition thresholds. American Journal of Psychology, 88, 583-594.

FERRAND, L. (2000). Reading aloud polysyllabic words and nonwords: The syllabic length effect reexamined. Psychonomic Bulletin \& Review, 7, 142-148.

FERrAND, L., \& NEw, B. (2003). Syllabic length effects in visual word recognition and naming. Acta Psychologica, 113, 167-183.

Frederiksen, J. R., \& Kroll, J. F. (1976). Spelling and sound: Approaches to the internal lexicon. Journal of Experimental Psychology: Human Perception \& Performance, 2, 361-379.

Grainger, J., \& Jacobs, A. M. (1996). Orthographic processing in visual word recognition: A multiple read-out model. Psychological Review, 103, 518-565.

Howes, D. H., \& Solomon, R. L. (1951). Visual duration threshold as a function of word-probability. Journal of Experimental Psychology, 41, 401-410.

Hudson, P. T. W., \& Bergman, M. W. (1985). Lexical knowledge in word recognition: Word length and word frequency in naming and lexical decision tasks. Journal of Memory \& Language, 24, 46-58.

JuHASZ, B. J., \& RAYNER, K. (2003). Investigating the effects of a set of intercorrelated variables on eye fixation durations in reading. Journal 
of Experimental Psychology: Learning, Memory, \& Cognition, 29, $1312-1318$.

Lund, K., \& Burgess, C. (1996). Producing high-dimensional semantic spaces from lexical co-occurrence. Behavior Research Methods, Instruments, \& Computers, 28, 203-208.

McGinnies, E., Comer, P. B., \& LACEY, O. L. (1952). Visual-recognition thresholds as a function of word length and word frequency. Journal of Experimental Psychology, 44, 65-69.

MonseLL, S. (1991). The nature and locus of word frequency effects in reading. In D. Besner \& G. W. Humphreys (Eds.), Basic processes in reading: Visual word recognition (pp. 148-197). Hillsdale, NJ: Erlbaum.

Nazir, T. [A.], Ben-Boutayab, N., Decoppet, N., Deutsch, A., \& FROST, R. (2004). Reading habits, perceptual learning, and the recognition of printed words. Brain \& Language, 88, 294-311.

NAZIR, T. A., JACOBS, A. M., \& O'Regan, J. K. (1998). Letter legibility and visual word recognition. Memory \& Cognition, 26, 810-821.

Newbigging, P. L., \& HaY, J. (1962). The practice effect in recognition threshold determinations as a function of word frequency and length. Canadian Journal of Psychology, 16, 177-184.

O'Regan, J. K., \& JACOBS, A. M. (1992). Optimal viewing position effect in word recognition: A challenge to current theory. Journal of Experimental Psychology: Human Perception \& Performance, 18, 185-197.

Perry, C., \& Ziegler, J. C. (2002). A cross-language computational investigation of the length effect in reading aloud. Journal of Experimental Psychology: Human Perception \& Performance, 28, 9901001.

Postman, L., \& Adis-Castro, G. (1957). Psychophysical methods in the study of word recognition. Science, 125, 193-194.

Rayner, K., Sereno, S. C., \& Raney, G. E. (1996). Eye movement control in reading: A comparison of two types of models. Journal of Experimental Psychology: Human Perception \& Performance, 22, 1188-1200.
Richards, L. G., \& Heller, F. P. (1976). Recognition thresholds as a function of word length. American Journal of Psychology, 89, 455466.

RichaRDSON, J. T. E. (1976). The effects of stimulus attributes on latency of word recognition. British Journal of Psychology, 67, 315-325.

Spieler, D. H., \& BALOTA, D. A. (1997). Bringing computational models of word naming down to the item level. Psychological Science, 8, 411-416.

Vitu, F., O’Regan, J. K., \& Mittau, M. (1990). Optimal landing position in reading isolated words and continuous text. Perception \& Psychophysics, 47, 583-600.

WeEKES, B. S. (1997). Differential effects of number of letters on word and nonword naming latency. Quarterly Journal of Experimental Psychology, 50A, 439-456.

Whitney, C., \& LAVIDOR, M. (2004). Why word length only matters in the left visual field. Neuropsychologia, 42, 1680-1688.

Ziegler, J. C., Perry, C., Jacobs, A. M., \& Braun, M. (2001). Identical words are read differently in different languages. Psychological Science, 12, 379-384.

\section{NOTE}

1. The ELP database also provides the reaction times expressed as $z$ scores on the individual subjects' distributions. This has the advantage of putting all subjects on the same scale. We ran analyses on the $z$ scores similar to the ones presented in this paper. They yielded exactly the same conclusion. We present the raw data here, because the regression weights on them have a straightforward interpretation: the savings and costs expressed in milliseconds.

(Manuscript received September 20, 2004; revision accepted for publication May 27, 2005.) 